\title{
DETERMINAN SUATU MATRIKS TOEPLITZ K-TRIDIAGONAL MENGGUNAKAN METODE REDUKSI BARIS DAN EKSPANSI KOFAKTOR
}

\author{
Rasmawati $^{1 *}$, Lailay Yahya ${ }^{2}$, Agusyarif Rezka Nuha $^{3}$, Resmawan $^{4}$ \\ 1,2,3,4 Jurusan Matematika, Universitas Negeri Gorontalo, Bone Bolango 96119, Indonesia \\ *Penulis Korespondensi. Email: rasmawati1407@gmail.com
}

\begin{abstract}
Abstrak
Tulisan ini membahas tentang determinan suatu matriks Toeplitz k-tridiagonal dengan menggunakan metode reduksi baris dan ekspansi kofaktor. Analisis dilakukan secara rekursif dari bentuk umum determinan matriks Toeplitz tridiagonal, determinan matriks Toeplitz 2-tridiagonal dan determinan matriks Toeplitz 3-tridiagonal. Pada akhirnya, diperoleh bentuk umum determinan matriks Toeplitz k-tridiagonal.
\end{abstract}

Kata Kunci: Determinan; Matriks Teoplitz k-Tridiagonal; Reduksi Baris; Ekspansi Kofaktor

\begin{abstract}
This paper discusses the determinants of a k-tridiagonal Toeplitz matrix using row reduction and cofactor expansion methods. The analysis was carried out recursively from the general form of the determinant of the tridiagonal Toeplitz matrix, the determinant of the 2-tridiagonal Toeplitz matrix, and the determinant of the 3-tridiagonal Toeplitz matrix. In the end, the general form of the determinant of the k-tridiagonal Toeplitz matrix is obtained.
\end{abstract}

Keywords: Determinant; -Tridiagonal Teoplitz Matrix; Row Reduction; Cofactor Expansion

\section{Pendahuluan}

Salah satu cabang dari ilmu matematika adalah aljabar linear yang di dalamnya membahas tentang matriks. Matriks merupakan salah satu materi dasar untuk mempelajari ilmu matematika khususnya tentang aljabar. Matriks adalah susunan segi empat siku-siku dari bilangan-bilangan, bilangan-bilangan dalam susunan tersebut dinamakan entri dari matriks, dalam matriks dikenal ukuran matriks yang disebut ordo yaitu banyaknya baris $\times$ banyaknya kolom [1].

Salah satu pembahasan dalam teori matriks yaitu menentukan determinan dari suatu matriks. Determinan mempunyai peranan penting dalam menyelesaikan beberapa persoalan dalam matriks dan banyak dipergunakan dalam ilmu matematika maupun ilmu terapannya. Menghitung nilai determinan suatu matriks terdapat beberapa metode yang dapat digunakan, diantara metode tersebut adalah metode reduksi baris, metode ekspansi kofaktor, serta metode corner. Menentukan nilai determinan matriks dengan ukuran yang kecil, tidaklah begitu sulit. Namun jika matriksnya berukuran besar, penentuan determinannya menjadi rumit. Sehingga diperlukan formula yang tepat untuk memudahkan penentuan determinan matriks. Dalam teori matriks juga terdapat berbagai jenis matriks, salah satunya matriks toeplitz. Pada dasarnya matriks toeplitz mempunyai operasi yang sama dengan matriks biasa hanya saja pada matriks toeplitz mempunyai struktur dan sifat yang khusus. Matriks toeplitz adalah matriks simetris yang sirkulan dimana setiap unsur pada diagonal utamanya sama dan setiap unsur pada subdiagonal yang bersesuaian dengan diagonal utama juga sama. 
Salah satu jenis dari matriks toeplitz yaitu matriks toeplitz tridiagonal. Menurut Salkuyeh [2], suatu matriks toeplitz tridiagonal berorde $n$ adalah suatu matriks yang berbentuk:

$$
A=\left[\begin{array}{cccccc}
b & a & 0 & 0 & \cdots & 0 \\
c & b & a & 0 & \cdots & 0 \\
0 & c & b & a & \cdots & 0 \\
\vdots & \vdots & \vdots & \vdots & \ddots & \vdots \\
0 & 0 & \cdots & c & b & a \\
0 & 0 & \cdots & 0 & c & b
\end{array}\right] .
$$

Matriks jenis ini sudah beberapa kali dibahasa pada penelitian-penelitian sebelumnya, diantaranya dilakukan oleh Siregar [3] yang menunjukkan bahwa determinan matriks toeplitz yang memiliki bentuk khusus seperti berikut ini,

$$
T_{n}=\left[\begin{array}{cccc}
0 & x & \cdots & x \\
x & 0 & \cdots & x \\
\vdots & \vdots & \ddots & \vdots \\
x & x & \cdots & 0
\end{array}\right] \forall \in \mathrm{R}
$$

memiliki determinan

$$
\left|T_{n}\right|=(-1)^{n}(n-1) x^{n} .
$$

Hal ini menunjukkan bahwa terdapat rumus khusus untuk menentukan determinan dari matriks toeplitz. Perhitungan determinan tidak perlu lagi melalui serangkaian proses yang panjang dan rumit, namun cukup dengan mensubstitusi entri-entri atau ukuran matriks yang akan dicari determinannya. Lebih lanjut, Borowska dan Lacinska [4] juga telah melakukan kajian terkait hubungan nilai eigen matriks toeplitz 2-tridiagonal dengan matriks toeplitz tridiagonal. Penelitian-penelitian terbaru yang secara khusus membahas tentang matriks Toeplitz k-Tridiagonal dapat ditemukan pada [5]-[8]. Beberapa pembahasan ini secara spesifik belum ada yang membahas tentang determinan matriks ktridiagonal.

Pada makalah ini dibahas bentuk umum determinan matriks toeplitz k-tridiagonal yang belum ditemukan pada beberapa penelitian sebelumnya. Formulasi khusus/bentuk umum determinan matriks toeplitz k-tridiagonal ditentukan dengan menggunakan metode reduksi baris dan ekspansi kofaktor.

\section{Metode Penelitian}

Tedapat banyak jenis-jenis matriks, salah satunya adalah matriks toeplitz. Berikut diberikan definisi matriks toeplitz.

Definisi Gray [9] Sebuah matriks teoplitz adalah matriks berukuran $n \times n$ dinotasikan sebagai $T_{n}=$ $\left[t_{k j} ; k, j=0,1, \ldots, n-1\right]$ dengan $t_{k j}=t_{k-j}$ sebuah matriks dengan formula (3)

$$
T_{n}=\left[\begin{array}{ccccc}
t_{0} & t_{-1} & t_{-2} & \cdots & t_{-(n-1)} \\
t_{1} & t_{0} & t_{-1} & \cdots & t_{-(n-2)} \\
t_{2} & t_{1} & t_{0} & \cdots & t_{-(n-3)} \\
\vdots & \vdots & \vdots & \ddots & \vdots \\
t_{n-1} & t_{n-2} & \cdots & t_{1} & t_{0}
\end{array}\right]
$$

Matriks ini diberi nama matriks toeplitz sebagaimana penemunya yaitu Otto Toeplitz, seorang matematikawan berkebangsaan Jerman di awal abad 20. Salah satu jenis dari matriks toeplitz adalah matriks toeplitz tridiagonal. Bentuk matriks toeplitz tridiagonal orde $n$ pada persamaan (1), dimana $a \neq 0$ dan $c \neq 0[3]$.

Dari matriks toeplitz tridiagonal ini dapat diperoleh matriks toeplits k-tridiagonal, Matriks ktridiagonal umum $A_{n}^{(k)}$ dapat ditulis dalam bentuk 


$$
A_{n}^{(k)}=\left[a_{i j}\right]_{n \times n}
$$

Jika

$$
\left\{\begin{array}{rr}
a, & i=j \\
b, & i-j=k \\
c, & j-i=k \\
0, & i, j, i-j, k, j-i, k
\end{array}\right.
$$

Dapat dicatat bahwa matriks tridiagonal (3) adalah kasus khusus dari matriks k-tridiagonal (4), ketika $k=1$. Jika $k=2$ maka matriks ini memiliki bentuk (2)

$$
A_{n}^{(k)}=\left[\begin{array}{cccccc}
a & 0 & c & 0 & \cdots & 0 \\
0 & a & 0 & c & \cdots & \cdots \\
\ddots & \ddots & \ddots & \ddots & \ddots & \ddots \\
\cdots & \cdots & 0 & a & 0 & c \\
\cdots & \cdots & b & 0 & a & 0 \\
0 & \cdots & 0 & b & 0 & a
\end{array}\right]
$$

Ada beberapa metode untuk menentukan determinan dari matriks bujur sangkar yaitu metode sarrus, metode reduksi baris, metode eliminasi gauss, metode ekspansi kofaktor. Berdasarkan beberapa metode tersebut, penulis menggunakan dua metode yaitu metode reduksi baris dan ekspansi kofaktor.

\subsection{Metode Reduksi Baris}

Metode ini merupakan salah satu cara untuk mengetahui determinan suatu matriks tidak memerhatikan seberapa besar ukuran matriks tersebut. Metode ini penting untuk menghindari perhitungan pajang yang terlibat dalam penerapan definisi determinan secara langsung. Jika $A$ memuat dua baris yang saling berkelipatan atau dua kolom yang saling berkelipatan, maka $\operatorname{det}(A)=$ 0 . Jika $A$ matriks segitiga maka $\operatorname{det}(A)=a_{11} a_{22} \ldots a_{n n}$ perkalian $n$ dari semua entri pada diagonal utama [10].

\subsection{Metode Ekspansi Kofaktor}

Misalkan $A_{n \times n}=\left[a_{i j}\right]$, maka minor dari $a_{i j}$,yang dilambangkan oleh $M_{i j}$, adalah determinan dari submatriks A yang diperoleh dengan cara membuang semua entri pada baris ke-i dan semua entri pada kolom ke-j. Sedangkan kofaktor dari $a_{i j}$, yang dilambangkan oleh $C_{i j}$, adalah $(-1)^{i+j} M_{i j}$. Determinan matriks $A$ yang berukuran $n \times n$ dapat dihitung dengan mengalikan entri-entri dalam suatu baris atau kolom dengan kofaktor-kofaktornya dan menambahkan hasil-hasil kali yang dihasilkan; yakni, untuk setiap $1 \leq i \leq n$ dan $1 \leq j \leq n$, maka $\operatorname{det}(A)=a_{1 j} C_{1 j}+a_{2 j} C_{2 j}+\cdots+$ $\cdots a_{n j} C_{n j}$ (ekspansi kofaktor sepanjang kolom ke j), $\operatorname{dan} \operatorname{det}(A)=a_{i 1} C_{i 1}+a_{i 2} C_{i 2}+\cdots+\cdots a_{i n} C_{i n}$ (ekspansi kofaktor sepanjang baris ke i) [10].

Metode penelitian yang digunakan adalah studi literatur, terdapat beberapa langkah yang dikerjakan. Pertama menentukan determinan matriks toeplitz tridiagonal ordo $2 \times 2$ sampai $5 \times 5$ dan matriks toeplitz 2-tridiagonal ordo $3 \times 3$ sampai $6 \times 6$ dengan menggunakan kombinasi metode reduksi baris dan ekspansi kofaktor, menduga bentuk umum determinan matriks toeplitz tridiagonal dan matriks toeplitz 2-tridiagonal dengan memperhatikan pola rekursifnya. Kedua membuktikan bentuk umum determinan matriks toeplitz tridiagonal dan matriks toeplitz 2-tridiagonal dengan menggunakan metode ekspansi kofaktor. Ketiga merumuskan bentuk determinan secara umum dari matriks toeplitz 3-tridiagonal. Keempat membuktikan rumus determinan dari matriks toeplitz 3tridiagonal yang berorde $n \times n$ yang diperoleh menggunakan metode ekspansi kofaktor. Kelima merumuskan bentuk determinan secara umum dari matriks toeplitz k-tridiagonal. Keenam 
membuktikan rumus determinan dari matriks Toeplitz $k$-tridiagonal yang berorde $n \times n$ yang diperoleh menggunakan ekspansi kofaktor.

\section{Hasil dan Pembahasan}

\subsection{Matriks Toeplitz Tridiagonal}

Diberikan matriks toeplitz tridiagonal ordo $2 \times 2$ sampai $5 \times 5$ sebagai berikut:

$$
T_{2}^{(1)}=\left[\begin{array}{ll}
a & c \\
b & a
\end{array}\right]
$$

Dapat langsung diperoleh

$$
\left|T_{2}^{(1)}\right|=a^{2}-b c
$$

Lalu diberikan matriks toeplitz tridiagonal ordo $3 \times 3$ sebagai berikut:

$$
T_{3}^{(1)}=\left[\begin{array}{lll}
a & c & 0 \\
b & a & c \\
0 & b & a
\end{array}\right]
$$

Langkah pertama yang dilakukan adalah mereduksi matriks yang diberikan melalui operasi baris elementer hingga terdapat suatu baris atau kolom yang banyak memuat entri nol (hanya satu yang bukan nol).

$$
T_{3}^{(1)}=\left[\begin{array}{lll}
a & c & 0 \\
b & a & c \\
0 & b & a
\end{array}\right] B_{2}+\left(-\frac{b}{a} \cdot B_{1}\right)
$$

diperoleh

$$
T_{3}^{(1)}=\left[\begin{array}{ccc}
a & c & 0 \\
0 & \frac{a^{2}-b c}{a} & c \\
0 & b & a
\end{array}\right]
$$

selanjutnya adalah melakukan ekspansi kofaktor sepanjang baris atau kolom yang banyak memuat entri nol. Pada kasus ini dipilih ekspansi kofaktor sepanjang kolom pertama dengan rumus $a_{11} C_{11}+$ $a_{21} C_{21}+a_{31} C_{31}$, sehingga diperoleh

$$
\left|T_{3}^{(1)}\right|=a\left[\begin{array}{cc}
\frac{a^{2}-b c}{a} & c \\
b & a
\end{array}\right]
$$

jadi, determinan dari $\left|T_{3}^{(1)}\right|$ adalah

$$
\begin{gathered}
\left|T_{3}^{(1)}\right|=a\left(\left(a^{2}-b c\right)-(b c)\right) \\
\left|T_{3}^{(1)}\right|=a^{3}-a b c-a b c \\
\left|T_{3}^{(1)}\right|=a^{3}-2 a b c
\end{gathered}
$$

Dengan menggunakan cara yang sama seperti sebelumnya didapat determinan matriks toeplitz tridiagonal menggunakan kombinasi reduksi baris dan ekspansi kofaktor

$\left|T_{4}^{(1)}\right|=a^{4}-3 a^{2} b c+b^{2} c^{2}$ 
$\left|T_{5}^{(1)}\right|=a^{5}-4 a^{3} b c+3 a b^{2} c^{2}$

Dari urutan determinan diatas dapat diperoleh bentuk umum matriks toeplitz tridiagonal ordo $n \times n$ dimana $n \geq 2$ dinyatakan sebagai:

Teorema 1. Bentuk Umum Determinan Matriks Toeplitz Tridiagonal

Andaikan $T_{n}^{(1)}$ adalah suatu matriks toeplitz tridiagonal berordo $n \times n$ maka determinan dari matriks $T_{n}^{(1)}$ dapat dinyatakan sebagai berikut

$$
\left|T_{n}^{(1)}\right|=a\left|T_{n-1}^{(1)}\right|-b c\left|T_{n-2}^{(1)}\right|
$$

$\operatorname{dimana}\left|T_{0}^{(1)}\right|=1$ dan $\left|T_{1}^{(1)}\right|=a$

Bukti. Pembuktian dilakukan dengan ekspansi kofaktor $T_{n}^{(1)}$

$$
\left|T_{n}^{(1)}\right|=\left|\begin{array}{cccccc}
a & c & 0 & 0 & \cdots & 0 \\
b & a & c & 0 & \cdots & \cdots \\
0 & b & a & c & \cdots & \cdots \\
\vdots & \ddots & \ddots & \ddots & \ddots & \vdots \\
\cdots & \cdots & b & a & c & 0 \\
\cdots & \cdots & 0 & b & a & c \\
0 & \cdots & 0 & 0 & b & a
\end{array}\right|_{n \times n}
$$

Menggunakan ekspansi kofaktor untuk $T_{n}^{(1)}$ disepanjang kolom pertama

$$
\left|T_{n}^{(1)}\right|=a\left|\begin{array}{cccccc}
a & c & 0 & 0 & \cdots & 0 \\
b & a & c & 0 & \cdots & \cdots \\
0 & b & a & c & \cdots & \cdots \\
\vdots & \ddots & \ddots & \ddots & \ddots & \vdots \\
\cdots & \cdots & b & a & c & 0 \\
\cdots & \cdots & 0 & b & a & c \\
0 & \cdots & 0 & 0 & b & a
\end{array}\right|_{n-1 \times n-1}\left|\begin{array}{cccccc}
c & 0 & 0 & 0 & \cdots & 0 \\
b & a & c & 0 & \cdots & \cdots \\
0 & b & a & c & \cdots & \cdots \\
\vdots & \ddots & \ddots & \ddots & \ddots & \vdots \\
\cdots & \cdots & b & a & c & 0 \\
\cdots & \cdots & 0 & b & a & c \\
0 & \cdots & 0 & 0 & b & a
\end{array}\right|_{n-1 \times n-1}
$$

Selanjutnya melakukan ekspansi kofaktor sepanjang baris pertama, jadi didapatkan

$$
\left|T_{n}^{(1)}\right|=a\left|T_{n-1}^{(1)}\right|-b c\left|\begin{array}{cccccc}
a & c & 0 & 0 & \cdots & 0 \\
b & a & c & 0 & \cdots & \cdots \\
0 & b & a & c & \cdots & \cdots \\
\vdots & \ddots & \ddots & \ddots & \ddots & \vdots \\
\cdots & \cdots & b & a & c & 0 \\
\cdots & \cdots & 0 & b & a & c \\
0 & \cdots & 0 & 0 & b & a
\end{array}\right|_{n-2 \times n-2}
$$

Dengan demikian terbukti bahwa $\left|T_{n}^{(1)}\right|=a\left|T_{n-1}^{(1)}\right|-b c\left|T_{n-2}^{(1)}\right|$.

\subsection{Matriks Toeplitz 2-Tridiagonal}

Diberikan matriks toeplitz 2-tridiagonal ordo $3 \times 3$ sampai $6 \times 6$ sebagai berikut:

$$
T_{3}^{(2)}=\left[\begin{array}{lll}
a & 0 & c \\
0 & a & 0 \\
b & 0 & a
\end{array}\right]
$$


Langkah pertama yang dilakukan adalah mereduksi matriks yang diberikan melalui operasi baris elementer hingga terdapat suatu baris atau kolom yang banyak memuat entri nol (hanya satu yang bukan nol).

$$
\begin{aligned}
T_{3}^{(2)} & =\left[\begin{array}{lll}
a & 0 & c \\
0 & a & 0 \\
b & 0 & a
\end{array}\right] B_{3}+\left(-\frac{b}{a} \cdot B_{1}\right) \\
T_{3}^{(2)} & =\left[\begin{array}{ccc}
a & 0 & c \\
0 & a & 0 \\
0 & 0 & \frac{a^{2}-b c}{a}
\end{array}\right]
\end{aligned}
$$

Selanjutnya adalah melakukan ekspansi kofaktor sepanjang baris atau kolom yang banyak memuat entri nol. Pada kasus ini dipilih ekspansi kofaktor sepanjang kolom pertama dengan rumus $a_{11} C_{11}+$ $a_{21} C_{21}+a_{31} C_{31}$. Sehingga diperoleh

$$
\left|T_{3}^{(2)}\right|=a\left[\begin{array}{cc}
a & 0 \\
0 & \frac{a^{2}-b c}{a}
\end{array}\right]
$$

Jadi determinan dari $T_{3}^{(2)}$ adalah

$$
\begin{gathered}
\left|T_{3}^{(2)}\right|=a(a)\left(\frac{a^{2}-b c}{a}\right) \\
\left|T_{3}^{(2)}\right|=a^{3}-a b c
\end{gathered}
$$

Dengan menggunakan cara yang sama seperti sebelumnya didapat determinan matriks toeplitz 2-tridiagonal menggunakan kombinasi reduksi baris dan ekspansi kofaktor

$\left|T_{4}^{(2)}\right|=a^{4}-2 a^{2} b c+b^{2} c^{2}$

$\left|T_{5}^{(2)}\right|=a^{5}-3 a^{3} b c+2 a b^{2} c^{2}$

$\left|T_{6}^{(2)}\right|=a^{6}-4 a^{4} b c+4 a^{2} b^{2} c^{2}$

Dari urutan determinan diatas dapat diperoleh bentuk umum matriks toeplitz 2-tridiagonal ordo $n \times n$ dimana $n \geq 3$ dinyatakan sebagai:

Teorema 2. Bentuk Umum Determinan Matriks Toeplitz 2-Tridiagonal

Andaikan $T_{n}^{(2)}$ adalah suatu matriks toeplitz tridiagonal berordo $n \times n$ maka determinan dari matriks $T_{n}^{(2)}$ dapat dinyatakan sebagai berikut

$$
\left|T_{n}^{(2)}\right|=a\left|T_{n-1}^{(2)}\right|-a b c\left|T_{n-3}^{(2)}\right|-b^{2} c^{2}\left|T_{n-4}^{(2)}\right|
$$

$\operatorname{dimana}\left|T_{-1}^{(2)}\right|=0,\left|T_{0}^{(2)}\right|=1,\left|T_{1}^{(2)}\right|=a$ dan $\left|T_{2}^{(2)}\right|=a^{2}$

Bukti. Pembuktian dilakukan dengan ekspansi kofaktor $T_{n}^{(2)}$ 


$$
\left|T_{n}^{(2)}\right|=\left|\begin{array}{ccccccc}
a & 0 & c & 0 & 0 & \cdots & 0 \\
0 & a & 0 & c & 0 & \cdots & \cdots \\
b & 0 & a & 0 & c & \cdots & \cdots \\
\vdots & \ddots & \ddots & \ddots & \ddots & \ddots & \vdots \\
\cdots & \cdots & b & 0 & a & 0 & 0 \\
\cdots & \cdots & 0 & b & 0 & a & 0 \\
0 & \cdots & 0 & 0 & b & 0 & a
\end{array}\right|_{n \times n}
$$

Menggunakan ekspansi kofaktor untuk $\left|T_{n}^{(2)}\right|$ disepanjang kolom pertama

$$
\left|T_{n}^{(2)}\right|=a\left|\begin{array}{ccccccc}
a & 0 & c & 0 & 0 & \cdots & 0 \\
0 & a & 0 & c & 0 & \cdots & \cdots \\
b & 0 & a & 0 & c & \cdots & \cdots \\
\vdots & \ddots & \ddots & \ddots & \ddots & \ddots & \vdots \\
\cdots & \cdots & b & 0 & a & 0 & 0 \\
\cdots & \cdots & 0 & b & 0 & a & 0 \\
0 & \cdots & 0 & 0 & b & 0 & a
\end{array}\right|_{n-1 \times n-1} \quad+b\left|\begin{array}{ccccccc}
0 & c & 0 & 0 & 0 & \cdots & 0 \\
a & 0 & c & 0 & 0 & \cdots & \cdots \\
b & 0 & a & 0 & c & \cdots & \cdots \\
\vdots & \ddots & \ddots & \ddots & \ddots & \ddots & \vdots \\
\cdots & \cdots & b & 0 & a & 0 & 0 \\
\cdots & \cdots & 0 & b & 0 & a & 0 \\
0 & \cdots & 0 & 0 & b & 0 & a
\end{array}\right|_{n-1 \times n-1}
$$

Selanjutnya melakukan ekspansi kofaktor pada baris pertama, jadi didapatkan

$$
\left|T_{n}^{(2)}\right|=a\left|T_{n-1}^{(2)}\right|-b c\left|\begin{array}{ccccccc}
a & c & 0 & 0 & 0 & \cdots & 0 \\
b & a & 0 & c & 0 & \cdots & \cdots \\
0 & 0 & a & 0 & c & \cdots & \cdots \\
\vdots & \ddots & \ddots & \ddots & \ddots & \ddots & \vdots \\
\cdots & \cdots & b & 0 & a & 0 & 0 \\
\cdots & \cdots & 0 & b & 0 & a & 0 \\
0 & \cdots & 0 & 0 & b & 0 & a
\end{array}\right|_{n-2 \times n-2}
$$

Kemudian kembali melakukan ekspansi kofaktor di sepanjang baris pertama. Sehingga diperoleh

$$
\begin{aligned}
& \left|T_{n}^{(2)}\right|=a\left|T_{n-1}^{(2)}\right|-a b c\left|\begin{array}{ccccccc}
a & 0 & c & 0 & 0 & \cdots & 0 \\
0 & a & 0 & c & 0 & \cdots & \cdots \\
b & 0 & a & 0 & c & \cdots & \cdots \\
\vdots & \ddots & \ddots & \ddots & \ddots & \ddots & \vdots \\
\cdots & \cdots & b & 0 & a & 0 & 0 \\
\cdots & \cdots & 0 & b & 0 & a & 0 \\
0 & \cdots & 0 & 0 & b & 0 & a
\end{array}\right|_{n-3 \times n-3} \\
& +b c^{2}\left|\begin{array}{ccccccc}
b & 0 & c & 0 & 0 & \cdots & 0 \\
0 & a & 0 & c & 0 & \cdots & \cdots \\
0 & 0 & a & 0 & c & \cdots & \cdots \\
\vdots & \ddots & \ddots & \ddots & \ddots & \ddots & \vdots \\
\cdots & \cdots & b & 0 & a & 0 & 0 \\
\cdots & \cdots & 0 & b & 0 & a & 0 \\
0 & \cdots & 0 & 0 & b & 0 & a
\end{array}\right|_{n-3 \times n-3}
\end{aligned}
$$

Selanjutnya dilakukan kembali ekspansi kofaktor di sepanjang kolom pertama, diperoleh

$$
\left|T_{n}^{(2)}\right|=a\left|T_{n-1}^{(2)}\right|-a b c\left|T_{n-3}^{(2)}\right|+b^{2} c^{2}\left|\begin{array}{ccccccc}
a & 0 & c & 0 & 0 & \cdots & 0 \\
0 & a & 0 & c & 0 & \cdots & \cdots \\
b & 0 & a & 0 & c & \cdots & \cdots \\
\vdots & \ddots & \ddots & \ddots & \ddots & \ddots & \vdots \\
\cdots & \cdots & b & 0 & a & 0 & 0 \\
\cdots & \cdots & 0 & b & 0 & a & 0 \\
0 & \cdots & 0 & 0 & b & 0 & a
\end{array}\right|_{n-4 \times n-4}
$$

Dengan demikian terbukti bahwa $\left|T_{n}^{(2)}\right|=a\left|T_{n-1}^{(2)}\right|-a b c\left|T_{n-3}^{(2)}\right|+b^{2} c^{2}\left|T_{n-4}^{(2)}\right|$. 


\subsection{Matriks Toelitz 3-Tridiagonal}

Bentuk umum matriks toeplitz 3-tridiagonal sebagai berikut:

$$
T_{n}^{(3)}=\left[\begin{array}{ccccccccc}
a & 0 & 0 & c & 0 & 0 & 0 & \cdots & 0 \\
0 & a & 0 & 0 & c & 0 & 0 & \cdots & \cdots \\
0 & 0 & a & 0 & 0 & c & 0 & \cdots & \cdots \\
b & 0 & 0 & a & 0 & 0 & c & \cdots & \cdots \\
\vdots & \ddots & \ddots & \ddots & \ddots & \ddots & \ddots & \ddots & \vdots \\
\cdots & \cdots & 0 & b & 0 & 0 & a & 0 & 0 \\
\cdots & \cdots & 0 & 0 & b & 0 & 0 & a & 0 \\
0 & \cdots & 0 & 0 & 0 & b & 0 & 0 & a
\end{array}\right]
$$

dimana $n \geq 3$ dan $k=3$

Teorema 3. Bentuk Umum Determinan Matriks Toeplitz 3-Tridiagonal

Andaikan $\left|T_{n}^{(3)}\right|$ adalah suatu matriks toeplitz 3-tridiagonal berordo $n \times n$ maka determinan dari matriks $\left|T_{n}^{(3)}\right|$ dapat dinyatakans ebagai berikut

$$
\left|T_{n}^{(3)}\right|=\mathrm{a}\left|T_{n-1}^{(3)}\right|-b c\left|T_{\left[\frac{n}{3} \mid-2\right.}^{(1)}\right|\left|T_{n-\left|\frac{n}{3}\right|}^{(2)}\right|
$$

dimana $\left|T_{3}^{(3)}\right|=a^{3}$ dan $\left\lceil\frac{n}{3}\right\rceil$ merupakan pembulatan keatas.

Bukti. Pembuktian dilakukan dengan ekspansi kofaktor $\left|T_{n}^{(3)}\right|$. Pada bukti teorema ini tidak akan ditulis matriks yang diperoleh dari setiap langkah ekspansi kofaktor dengan jelas seperti pada bukti teorema 1 dan bukti teorema 2. Namun hanya akan dituliskan langkah-langkah yang akan digunakan sebagai langkah kerjanya.

Langkah 1:

Dengan melakukan ekspansi kofaktor dari $\left|T_{n}^{(3)}\right|$ di sepanjang kolom pertama, diperoleh $\left|T_{n}^{(3)}\right|=a\left|T_{n-1}^{(3)}\right|-b\left|M_{n-1}\right|$

notasi $\left|M_{n-1}\right|$ merupakan determinan dari matriks dengan ordo $n-1 \times n-1$ yang tidak memenuhi bentuk (5)

Langkah 2:

Selanjutnya adalah melakukan ekspansi kofaktor di sepanjang baris pertama pada $\left|M_{n-1}\right|$, diperoleh $\left|T_{n}^{(3)}\right|=a\left|T_{n-1}^{(3)}\right|-b c\left|M_{n-2}\right|$

notasi $\left|M_{n-2}\right|$ merupakan determinan dari matriks dengan ordo $n-2 \times n-2$ yang tidak memenuhi bentuk (5).

Langkah-langkah selanjutnya akan dilanjutkan dengan mengekspansi kofaktor dari $\left|M_{n-2}\right|$ dan semua submatriks yang diperoleh dari mengekspansi kofaktor disepanjang kolom $(3+2 i)$, dimana $i=1,2,3,4, \cdots,\left\lceil\frac{n}{3}\right\rceil-2$. Jadi langkah selanjutnya adalah melakukan ekspansi kofaktor disepanjang kolom ke-5 dari $\left|M_{n-2}\right|$ sehingga diperoleh determinan matriks yang berordo $n-3 \times n-3$, kemudian dilakukan lagi ekspansi kofaktor disepanjang kolom ke-7 sehingga menghasilkan determinan matriks berordo $n-4 \times n-4$, dan kemudian dilakukan ekspansi kofaktor kembali dan mendapatkan determinan matriks ordo $n-5 \times n-5$ dan seterusnya. Proses ekspansi kofaktor 
disepanjang kolom ini secara keseluruhan diulangi sampai $\left\lceil\frac{n}{3}\right\rceil$ kali. Koefisien dari $\left|T_{n-\left\lceil\frac{n}{3}\right\rceil}^{(2)}\right|$ yang diperoleh merupakan polinomial dengan variabel $a, b$ dan $c$. Polinomial ini sesuai dengan $\left|T_{\left|\frac{n}{3}\right|-2}^{(1)}\right|$.

Dengan demikian $\left|T_{n}^{(3)}\right|=a\left|T_{n-1}^{(3)}\right|-b c\left|M_{n-2}\right|$ menjadi

$$
\left|T_{n}^{(3)}\right|=\mathrm{a}\left|T_{n-1}^{(3)}\right|-b c\left|T_{\left\lceil\frac{n}{3}\right]-2}^{(1)}\right|\left|T_{n-\left[\frac{n}{3}\right]}^{(2)}\right|
$$

Akibatnya, setelah langkah terakhir dari ekspansi kofaktor, diperoleh determinan matriks yang berordo $n-\left\lceil\frac{n}{3}\right\rceil \times n-\left\lceil\frac{n}{3}\right\rceil$, dimana matriks tersebut memiliki bentuk toeplitz 2-tridiagonal.

\subsection{Matriks Toeplitz k-Tridiagonal}

Bentuk umum matriks toeplitz k-tridiagonal sebagai berikut:

$$
T_{n}^{(k)}=\left[\begin{array}{ccccccccc}
a & 0 & \cdots & 0 & c & \cdots & \cdots & \cdots & 0 \\
0 & a & 0 & \cdots & 0 & c & 0 & \cdots & \vdots \\
\vdots & 0 & a & \ddots & \cdots & \ddots & \ddots & \ddots & \vdots \\
0 & \vdots & \ddots & \ddots & \ddots & \cdots & \ddots & \ddots & \vdots \\
b & 0 & \cdots & \ddots & a & \ddots & \cdots & 0 & c \\
\vdots & \ddots & \ddots & \cdots & \ddots & \ddots & \ddots & \cdots & 0 \\
\vdots & \cdots & \ddots & \ddots & \cdots & \ddots & a & 0 & \vdots \\
\vdots & \cdots & \cdots & \ddots & \ddots & \cdots & 0 & a & 0 \\
0 & \cdots & \cdots & \cdots & b & 0 & \cdots & 0 & a
\end{array}\right]
$$

Bentuk umum dari matriks toeplitz k-tridiagonal memenuhi persamaan rekursif pada teorema 4.

Teorema 4. Bentuk Umum Matriks Toeplitz k-Tridiagonal

Andaikan $T_{n}^{(k)}$ adalah suatu matriks toeplitz k-tridiagonal berordo $n \times n$ maka determinan dari matriks $T_{n}^{(k)}$ dapat dinyatakan sebagai berikut:

$$
\left|T_{n}^{(k)}\right|=\mathrm{a}\left|T_{n-1}^{(k)}\right|-b c\left|T_{\left\lceil\frac{n}{k}\right\rceil-2}^{(1)}\right| \mid \begin{gathered}
T_{n-\left\lceil\frac{n}{k}\right\rceil}^{(k-1)} \\
\mid
\end{gathered}
$$

dimana $n \geq k+1,\left|T_{s}^{(k)}\right|=a^{s}$ untuk $0 \leq s \leq k$, dan $\left\lceil\frac{n}{k}\right\rceil$ merupakan pembulatan angka keatas.

Bukti. Pembuktian pada teorema ini dilakukan dengan menggunakan analogi yang sama pada pembuktian teorema 3. Sebagai ilustrasi perhatikan penyelesaian matriks berikut yang berbentuk 4tridiagonal dengan ordo 18

\section{Langkah 1:}

Pertama-tama adalah melakukan ekspansi kofaktor sepanjang kolom pertama pada $\left|T_{18}^{(4)}\right|$, sehingga diperoleh

$\left|T_{18}^{(4)}\right|=a\left|T_{17}^{(4)}\right|-b\left|M_{17}\right|$

$\left|M_{17}\right|$ merupakan determinan matriks $17 \times 17$.

Langkah 2:

Melakukan ekspansi kofaktor disepanjang baris pertama pada $\left|M_{17}\right|$, dan diperoleh 
$\left|T_{18}^{(4)}\right|=a\left|T_{17}^{(4)}\right|-b c\left|M_{16}\right|$

$\left|M_{16}\right|$ merupakan determinan matriks ordo $16 \times 16$.

Langkah ini akan terus dilanjutkan dengan melakukan ekspansi kofaktor pada $\left|M_{16}\right|$ di sepanjang kolom $(3 i+2 i), i=1,2,3,4, \cdots,\left\lceil\frac{18}{4}\right\rceil-2$. Dengan demikian ekspansi kofaktor akan dilakukan disepanjang kolom ke 7,10 dan 13

Langkah 3:

Melakukan ekspansi kofaktor di sepanjang kolom ke-5 pada $\left|M_{16}\right|$, sehingga diperoleh

$\left|T_{18}^{(4)}\right|=a\left|T_{17}^{(4)}\right|-a b c\left|M_{2}\right|-b^{2} c\left|M_{3}\right|$

$\left|M_{2}\right|$ dan $\left|M_{3}\right|$ merupakan determinan matriks ordo $15 \times 15$ setelah langkah ke-3.

\section{Langkah 4:}

Melakukan ekspansi kofaktor di sepanjang kolom ke-10 pada $\left|M_{2}\right|$ dan $\left|M_{3}\right|$, diperoleh

$\left|T_{18}^{(4)}\right|=a\left|T_{17}^{(4)}\right|-a^{2} b c\left|M_{4}\right|-a b^{2} c\left|M_{5}\right|+b^{2} c^{2}\left|M_{6}\right|-b^{3} c\left|M_{7}\right|$

$\left|M_{4}\right|,\left|M_{5}\right|,\left|M_{6}\right|$ dan $\left|M_{7}\right|$ merupakan determinan matriks berordo $14 \times 14$ setelah langkah ke-4.

Langkah 5:

Melakukan ekspansi kofaktor di sepanjang kolom ke-13 pada $\left|M_{4}\right|,\left|M_{5}\right|,\left|M_{6}\right|$ dan $\left|M_{7}\right|$, diperoleh

$\left|T_{18}^{(4)}\right|=a\left|T_{17}^{(4)}\right|-a^{3} b c\left|M_{8}\right|+a b^{2} c^{2}\left|M_{9}\right|+a b^{2} c^{2}\left|M_{10}\right|-0$

$\left|M_{8}\right|,\left|M_{9}\right|$, dan $\left|M_{10}\right|$ merupakan determinan matriks berordo $13 \times 13$. Pengerjaan ini berakhir pada langkah ini karena matriks yang diperoleh merupakan bentuk matriks pada persamaan (5), dan juga karena jumlah langkah sama dengan $\left[\frac{18}{4}\right]$. Sehingga langkah 5 ini dapat dituliskan sebagai berikut

$$
\begin{aligned}
& \left|T_{18}^{(4)}\right|=a\left|T_{17}^{(4)}\right|-a^{3} b c\left|T_{13}^{(2)}\right|+a b^{2} c^{2}\left|T_{13}^{(2)}\right|+a b^{2} c^{2}\left|T_{13}^{(2)}\right| \\
& \left|T_{18}^{(4)}\right|=a\left|T_{17}^{(4)}\right|-\left(a^{3} b c-2 a b^{2} c^{2}\right)\left|T_{13}^{(2)}\right| \\
& \left|T_{18}^{(4)}\right|=a\left|T_{17}^{(4)}\right|-b c\left(a^{3}-2 a b c\right)\left|T_{13}^{(2)}\right| \\
& \left(a^{3}-2 a b c\right) \text { merupakan }\left|T_{3}^{(1)}\right|, \text { maka } \\
& \left|T_{18}^{(4)}\right|=a\left|T_{17}^{(4)}\right|-b c\left|T_{3}^{(1)}\right|\left|T_{3}^{(2)}\right| .
\end{aligned}
$$

\section{Kesimpulan}

Bentuk umum dari matriks toeplitz k-tridiagonal adalah:

$$
\left|T_{n}^{(k)}\right|=\mathrm{a}\left|T_{n-1}^{(k)}\right|-b c\left|T_{\left\lceil\frac{n}{k} \mid-2\right.}^{(1)}\right|\left|T_{n-\left|\frac{n}{k}\right|}^{(k-1)}\right|
$$

dimana $n \geq k+1,\left|T_{s}^{(k)}\right|=a^{s}$ untuk $0 \leq s \leq k$, dan $\left\lceil\frac{n}{k}\right\rceil$ merupakan pembulatan angka keatas. 


\section{Referensi}

[1] H. Anton, Aljabar Linear Elementer, Jakarta: Erlangga, 1997.

[2] D. K. Salkuyeh, "Positive Integer Powers of the Tridiagonal Toeplitz Matrices," in International Mathematical Forum Ardabil, Iran, 2006.

[3] B. Siregar, T. Tulus, and S. Sawaluddin, "Invers Suatu Matriks Toeplitz Menggunakan Metode Adjoin," Saintia Matematika, vol. 2, No. 1, pp. 85-94, 2014.

[4] J. Borowska, and L. Lacinska, "Eigenvalues of 2-Tridiagonal Toeplitz Matrix," Jurnal of applied mathematics and computation mechanics, vol. 14, no. 4, pp. 11-17, 2015.

[5] A. Z. Küçük, M. Özen, and H. Ince, H. "Recursive and combinational formulas for permanents of general k-tridiagonal Toeplitz matrices," Filomat, vol. 33, no. 1, pp. 307-317, 2019.

[6] C. M. da Fonseca, V. Kowalenko, and L. Losonczi, "Ninety years of k-tridiagonal matrices," Studia Scientiarum Mathematicarum Hungarica, vol. 57, no. 3, 298-311, 2020.

[7] A. Z. Kucuk, and M. Duz, "Relationships between the permanents of a certain type of ktridiagonal symmetric Toeplitz matrix and the Chebyshev polynomials," Journal of Applied Mathematics and Computational Mechanics, vol. 16, no. 1, 2017.

[8] A. Tănăsescu, and P.G. Popescu, "A fast singular value decomposition algorithm of general ktridiagonal matrices," Journal of Computational Science, vol. 31, pp. 1-5, 2019.

[9] R. M. Gray, "Toeplitz and Circulan Matrices," Departement of Electrical Engineering Stanford University., Stanford 94305, USA, 2005.

[10] I. E. Wijayanti, S. Wahyuni, and Y. Susanti, Dasar-Dasar Aljabar Linear dan Penggunaannya dalam Berbagai Bidang, UGM PRESS, 2018. 